\title{
Time course of antioxidant enzymes in the paraquat-resistant and tolerant Heary fleabane (Conyza bonariensis) biotypes in response to ozone exposure and paraquat application
}

\author{
C.T. DIOP ${ }^{1 *}$, L. MESSORI $^{2}$, D. HEIMLER ${ }^{3}$, C. NALI ${ }^{4}$ and G. LORENZINI ${ }^{4}$ \\ ${ }^{1}$ Institut Sénégalais de Recherches Agricoles (ISRA/UNIVAL), Pôle de recherches de Hann. BP 2241, Dakar, \\ Sénégal. \\ ${ }^{2}$ Département de Chimie, Université de Florence, rue G.Capponi 7-50121 Italie. \\ ${ }^{3}$ Chaire de Pathologie Végétale, Département CDSL, Université di Pise, rue Borghetto 80-56124, Pise, Italie \\ ${ }^{4}$ Département de Science du Sol et de la Nutrition de la plante, Université de Florence, Place des Cascine 15 - \\ 50144 Florence, Italie. \\ *Corresponding author; E-mail: cheikhtidiane.diop@isra.sn; cheikh56@hotmail.com
}

\begin{abstract}
In order to investigate the molecular mechanism of oxidative stress resistance due to either paraquat or ozone in plants, two paraquat biotypes (resistant and sensitive) of Conyza bonariensis were used. We monitored some biochemical parameters (total peroxydase, guaiacol peroxydase, ascorbate peroxydase and superoxyde dismutase) following a paraquat fumigation $(0.001 \%, 4$ hours), and a pulse of elevated ozone (200 ppb, 5 hours) or intermediate ozone (50 ppb, 4 hours). The mechanisms of protection induced by ozone exposure were not similar to the pathway leading to paraquat resistance, due to a different stimulation response system to antioxidants.
\end{abstract}

(C) 2019 International Formulae Group. All rights reserved

Keywords: Antioxidants, Halliwell-Asada cycle, Ozone, Paraquat, Conyza bonariensis.

\section{INTRODUCTION}

It has been observed that the parameters most commonly used in order to determinate the situation of stress due to ozone in a biochemical level and not visibly, consisted of the concentration of crucial metabolites, activities of enzymes and genes expression in plants leaves. From those various enzymes activities, a few of them selected and followed under conditions of ozone treatment.

In the context of behaviour evaluation of plants, exposed to ozone injury under controlled conditions, attention has been paid in the temporal evolution on followed parameters for such purpose. The parameter had been evaluated for many time points till at 96 hours, after ozone exposition, as also the dependence of the observed parameter, with the modalities of treatment following the dose, the time and the types of exposition.

We have investigated to correlate the parameter evolution type with the importance of the stress and the type of response induced in the plant. An attentive consideration has been devoted to the correlation metabolic change/active response; metabolic change/development of irreparable damage. In 
others words, we have searched to see what type of parameters evolution must be an indicator of positive response, or contrary an indice of sufference.

Finally, we have considerate if the biochemical parameters investigated can be used in fields for the aim of determining the situation in the beginning of stress due to ozone, before the visible damage. Certain sensitive plants to ozone are presently used in an experimental level for strategy of biomonitoring for evaluating the biological damage following the presence of ozone concentrations within urban agglomerations and metropolitan areas. Such studies are exclusively focused on morphological and anatomo-pathological datas. The application of this present method of bio-monitoring required an evaluation of the stress in a quantitative way, using the strict biochemical parameters and could help to determine and quantify the magnitude of the atmospheric pollution and possible interactions between the different toxical agents.

Heary fleabane, Conyza bonariensis (L.) Cronq, is a plant species which at the long run became insensitive to paraquat (1,1'dimethyl-4,4'-bipyridinoum) under field conditions (Lebaron \& Gressel, 1982). Two biotypes, one resistant and one sensitive to paraquat, have been isolated (Gressel, 1994). As ozone and paraquat are both oxidants inducing reactive oxygen substances (ROS) in plants, their action is postulated to have similar effects. Paraquat is a non-selective contact herbicide with a rapid dessicant action (Asthon \& Crafts, 1981). Paraquat competes for electrons from the primary electron acceptor of photosystem I. The paraquat free radicals formed are rapidly reoxidised by molecular oxygen, giving rise to superoxide radical anions (Stancliffe and Pirie, 1971). The superoxide can be either a potent oxidant by forming hydroxyl radicals or a reductant by forming singlet oxygen (Rabinovitch and Fridovitch, 1983). Superoxide dismutase can dismutate the superoxide to oxygen and hydrogen peroxide. Further reduction of hydrogen peroxide produces reactive hydroxyl radical causing lipid peroxidation and then membrane breakdown (Harris and Dodge, 1972). An ascorbate-glutathione cycle has been demonstrated for scavenging hydrogen peroxide by using ascorbate as electron donor with ascorbate peroxidase and glutathione reductase (Foyer and Halliwell, 1976). These two enzymes along with superoxide dismutase are normally at sufficient levels to enable chloroplasts to detoxify the superoxide produced by photosynthesis (Dodge, 1982).

Ground-level ozone $\left(\mathrm{O}_{3}\right)$ is the air pollutant of most concern to vegetation (Paoletti, 2007). Plants react to $\mathrm{O}_{3}$ by setting up a variety of defensive strategies (Castagna and Ranieri, 2009). Ozone-driven ROS production in the apoplast induces a secondary, active, self-propagating generation of ROS, whose levels must be finely tuned by many enzymatic and non-enzymatic antioxidant systems. When ROS formation exceeds the apoplastic antioxidant capacity, perception of $\mathrm{O}_{3}$-derived $\mathrm{ROS}$ induces an additional ROS production resulting in a selfpropagating secondary ROS generation which continues after the end of the $\mathrm{O}_{3}$ exposure and gives rise to a biphasic oxidative burst. A multitude of ROS-generating systems have been reported, such as peroxidases (PODs) (Castagna and Ranieri, 2009). The first line of defence is the apoplast, where ascorbate is provide an important protection (Ranieri et al., 1996). In addition to direct reaction with ROS, ascorbate may act as reducing substrate for ascorbate peroxidase, which is recognized as one of the most efficient ROS scavenging system (Foyer et al., 1994).

A lack of cross tolerance between ozone and paraquat has been already reported in Conyza bonarensis, by analysing physiological and antioxidant responses (Lorenzini et al., 2002). This paper investigated the time course of antioxidant enzymes (superoxide dismutase, total peroxidase, guaiacol peroxidase, ascorbate peroxidase) after paraquat or ozone exposure, in order to untangle similarities in their action.

\section{MATERIELS AND METHODS}

Plants material and treatments 
Two cultivars of C. bonariensis (paraquat resistant and sensitive) were selected. Seeds were germinated in a greenhouse, transferred to containers $(=9 \mathrm{~cm} \mathrm{x}$ $9 \mathrm{~cm})$ tourb : wet ground : perlide 1:1:1 and maintained under agronomic conditions. At the time plants had the primary (unifoliated) leaf fully expanded, more than 192 plants were selected for phenotypic uniformity and moved to a greenhouse (temperature $20 \pm 1$ ${ }^{\circ} \mathrm{C}, \mathrm{RH} 85 \pm 5 \%$ (VPD $0.4 \mathrm{kpa}$ ), PAR 530 $\mu \mathrm{mol} \mathrm{m} \mathrm{m}^{-2} \mathrm{~s}^{-1}, 14 \mathrm{~h}$ photoperiod). Prior to treatments, plants were pre-adapted to the greenhouse conditions for $24 \mathrm{~h}$. Paraquat was sprayed with a hand glass atomiser onto the leaves until drainage, using a commercial formulation having a concentration of $10 \mathrm{ppm}$ in distilled water, to which a drop of surfactant Tween 20 had been added. The experiment was replicated twice.

Exposure to ozone was carried out in a controlled environment fumigation apparatus (Lorenzini et al., 1994), that was continuously ventilated with charcoal-filtered air maintaining two complete air changes per min. Ozone was generated by electric discharge with a Fisher 500 air-cooled apparatus supplied with pure oxygen, and mixed with the inlet air entering the fumigation chamber. Its concentration in the chamber was continuously monitored with the photometric Monitored Labs analyzer, model 8810 , connected to a PC. Fumigations lasted $4 \mathrm{~h}$ or $5 \mathrm{~h}$ and the $\mathrm{O}_{3}$ concentrations were 50 ppb or $200 \mathrm{ppb}$, in order to simulate an asymptomatic and a symptomatic treatment, respectively. Control plants were maintained in charcoal-filtered air. Twenty four plants of each cultivar were used in each test. In total of 192 plants, 24 treatead versus 24 control, for 4 time points.

\section{Protein extraction}

One gramme of leave in $5 \mathrm{~cm}^{3}$. Whole primary leaves were collected at the end of the treatments and after $0,12,24$, and $48 \mathrm{~h}$, and the midvein was removed. The following analyses were carried out in triplicate on a bulk of leaves. The samples (1 $\mathrm{g}$ leaf powder in $5 \mathrm{~cm}^{3}$ of ice cold buffer) were homogenized with an Omnimixer Ultra Turax $(8,000 \mathrm{rpm}$ for $1 \mathrm{~min}$ ) in $66 \mathrm{mM}$ phosphate buffer $\mathrm{pH} 7.4$ containing $100 \mathrm{mM} \mathrm{NaCl}$ (Castillo and Greppin, 1986). After filtration through Miracloth (Calbiochem), the material was centrifuged with the Rotor Beckman J2HS AT $10,000 \mathrm{~g}$ for $10 \mathrm{~min}$. All operations were performed at $4{ }^{\circ} \mathrm{C}$. Aliquots of the supernatant were used to measure the enzymatic activities. Protein concentration of the enzyme extract was determined by the protein-dye binding method with BSA as the standard (Bradford, 1976).

\section{Determination of enzymatic activities}

Superoxide dismutase (SOD) activities were determined by the xanthine oxydase cytochrome $\mathrm{c}$ method (Mc Cord and Fridovitch 1969). Total peroxidase (PX) activity was monitored using 2,2 '-azino di[ethyl-benzothiazoline-(6) sulfonic acid] as substrate (Werner et al., 1970). The reaction was carried out at $\mathrm{pH} 6.0$, in the presence of 2 $\mathrm{mM}$ of ABTS and $1 \mathrm{mM} \mathrm{H}_{2} \mathrm{O}_{2}$ and monitored spectrophotometrically at $405 \mathrm{~nm}$. The absorbance increase at this wawelenth corresponds to the formation of $\mathrm{ABTS}^{+}$ cation, which is produced by the reaction. Guaiacol peroxidase (GPX) activity was determined in a reaction mixture that contained $50 \mathrm{mM} \mathrm{NaH} \mathrm{PO}_{4}(\mathrm{pH} 6.1), 16 \mathrm{mM}$, $2 \mathrm{Mm} \mathrm{H}_{2} \mathrm{O}_{2} \mathrm{PO}_{4}$ and $150 \mu \mathrm{l}$ of leaf extract (Castillo and Greppin, 1986). The activity were measured by monitoring the increase in absorbance at $470 \mathrm{~nm}$ during the polymerisation of guaiacol to tetraguaiacol. Ascorbate peroxidase (APX) activity was determined in a mixture $\left(1 \mathrm{~cm}^{3}\right)$ which contained $50 \mathrm{mM} \mathrm{Na} \mathrm{H}_{2} \mathrm{PO}_{4} \quad(\mathrm{pH}$ 7.0), $0.1 \mathrm{mM}$ EDTA, $0.5 \mathrm{mM}, 0.5 \mathrm{mM}$ ascorbic acid, $0.1 \mathrm{mM} \mathrm{H}_{2} \mathrm{O}_{2}$ and $150 \mu \mathrm{l}$ of leaf extract. The activity was measured by monitoring the rate of ascorbate oxidation at $290 \mathrm{~nm}(\epsilon=2.8$ $\mathrm{mM} \mathrm{cm} \mathrm{cm}^{-1}$ ) (Luwe et al., 1993). For all enzymatic activities, one arbitrary unit was calculated as the enzyme quantity that transforms $1 \mu \mathrm{mol}$ of substrate in $1 \mathrm{~min}$.

\section{RESULTS}

Macroscopic damage 


\section{Visible injury}

As expected, only the sensitive cv showed visible injury after the paraquat treatment, in the form of color change from green to yellow. It began from the petiole to the upper side of the limb where the paraquat is supposed to be diffused through the vascular tissue. After a symptomatic ozone treatment from the AOT40 to $200 \mathrm{ppb}$ for 5 hours, visible injury occurred in the form of small white necrotic lesions (mottles) in all over upper side of the leave. These symptoms occurred within 48 hours after either paraquat treatment or ozone fumigation.

\section{Total protein content}

The total leaf extractable protein content did not change significantly in response to $\mathrm{O}_{3}$ exposure and paraquat treatment.

\section{Enzymatic activities}

Exposure of plants to the herbicide paraquat at a symptomatic dose of $0.001 \%$ during $4 \mathrm{~h}$ induced a generalized increase of all the enzymes in both the biotypes (Figure 1 to Figure 8). The biological response occurred immediately and peaked at $24 \mathrm{~h}$. The increase of enzyme activities was generally $+50 \%$ to $100 \%$ versus controls. There was no visible difference in biochemical behaviour between the resistant and the sensitive biotype.

- Superoxide dismutase activity did not vary at all between resistant and sensitive cv, but versus control there was an increase of 2 -fold (Figure 1).

- Ascorbate peroxidase activity did not change between $\mathrm{cv}$ and versus controls (Figure 2). It seemed that constitutively there is enough to protect plant against stress.

- Total peroxidase showed a slight increase in the resistant $\mathrm{cv}$ relative controls (Figure 4).

Ozone symptomatic exposure induced a generalized increase of the investigated enzymes both in the sensitive $\mathrm{cv}$ and in the resistant cv (Figure 1 to Figure 4). There was 2 hours of lag time (particularly for APX during paraquat exposition). The maximum increase of enzyme activities was about $100 \%$ versus controls. There was a difference between the two $\mathrm{cv}$ for the SOD (Figure 1). The resistant cultivar had a maximal response of $100 \%$ (only $20 \%$ for the sensitive cultivar) versus control.

Total peroxidase increase rapidly in the paraquat sensitive cv Figure 5).

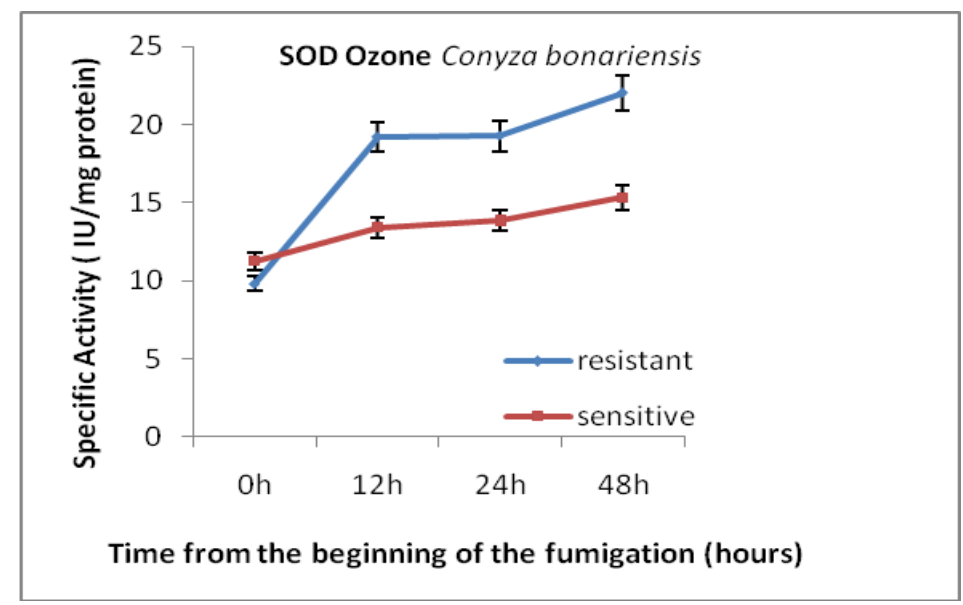

Figure 1: Time course of Superoxide dismutase activity in leaves extracts Conyza bonariensis (biotype resistant in closed circle and biotype sensitive in full triangle) exposed to ozone fumigation $200 \mathrm{ppb}$ for 5 hours. 


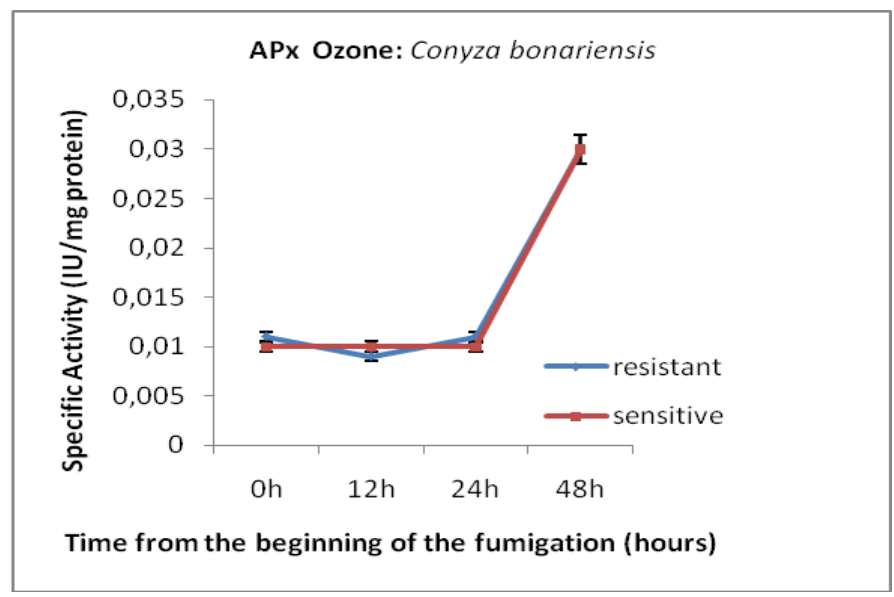

Figure 2: Time course of Ascorbate peroxidase activity in leaves extracts Conyza bonariensis (biotype resistant in closed circle and biotype sensitive in full triangle) exposed to ozone fumigation $200 \mathrm{ppb}$ for 5 hours.

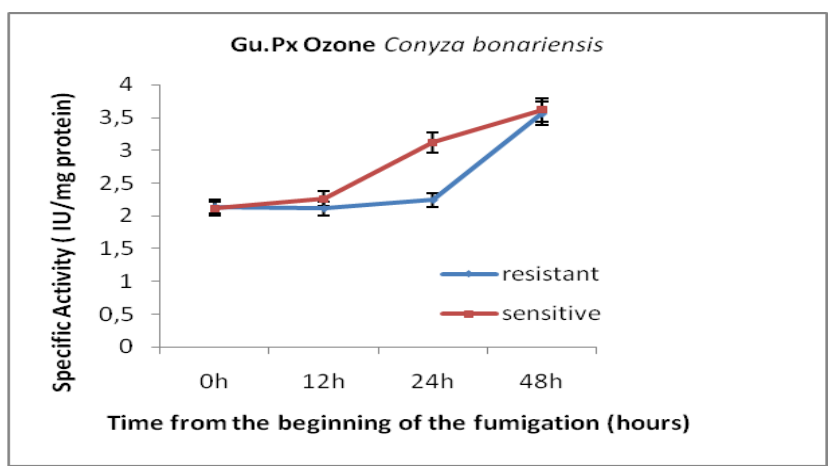

Figure 3: Time course of Guaiacol peroxidase activity in leaves extracts Conyza bonariensis (biotype resistant in closed circle and biotype sensitive in full triangle) exposed to ozone fumigation $200 \mathrm{ppb}$ for 5 hours.

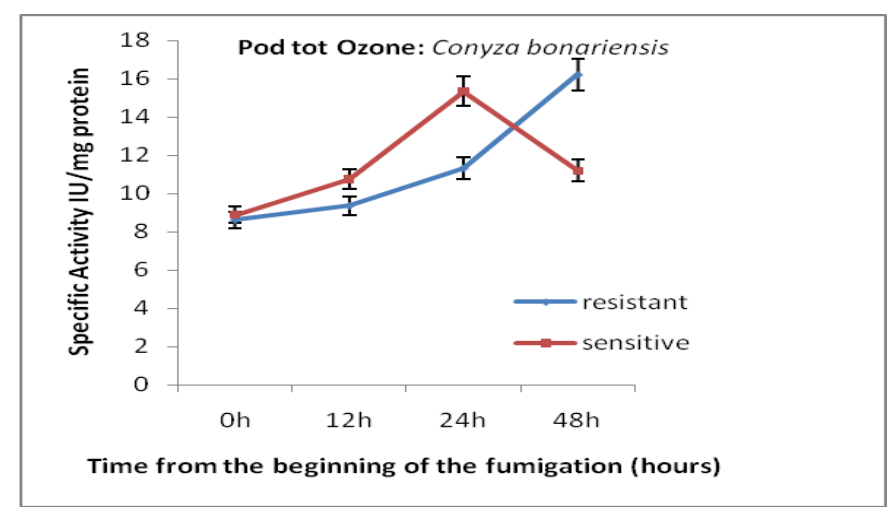

Figure 4: Time course of Total peroxidase activity in leaves extracts Conyza bonariensis (biotype resistant in closed circle and biotype sensitive in full triangle) exposed to ozone fumigation $200 \mathrm{ppb}$ for 5 hours. 


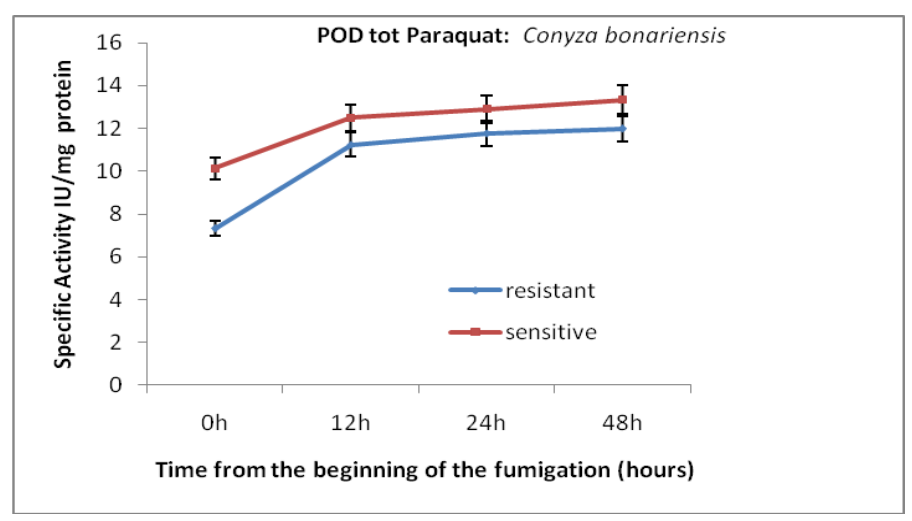

Figure 5: Time course of Total peroxidase activity in leaves extracts Conyza bonariensis (biotype resistant in closed circle and biotype sensitive in full triangle) after a treatment of paraquat $0.001 \%$ for 4 hours.

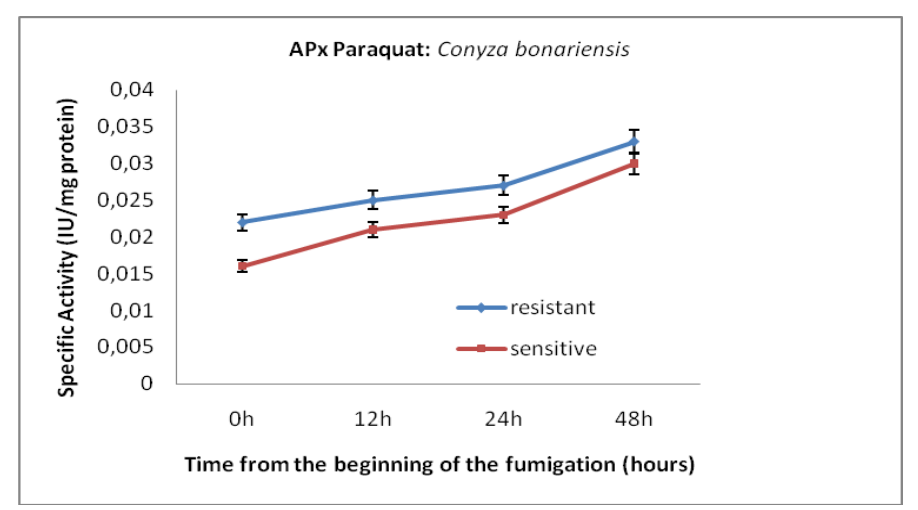

Figure 6: Time course of Ascorbate peroxidase activity in leaves extracts Conyza bonariensis (biotype resistant in closed circle and biotype sensitive in full triangle) after a treatment of paraquat $0.001 \%$ for 4 hours.

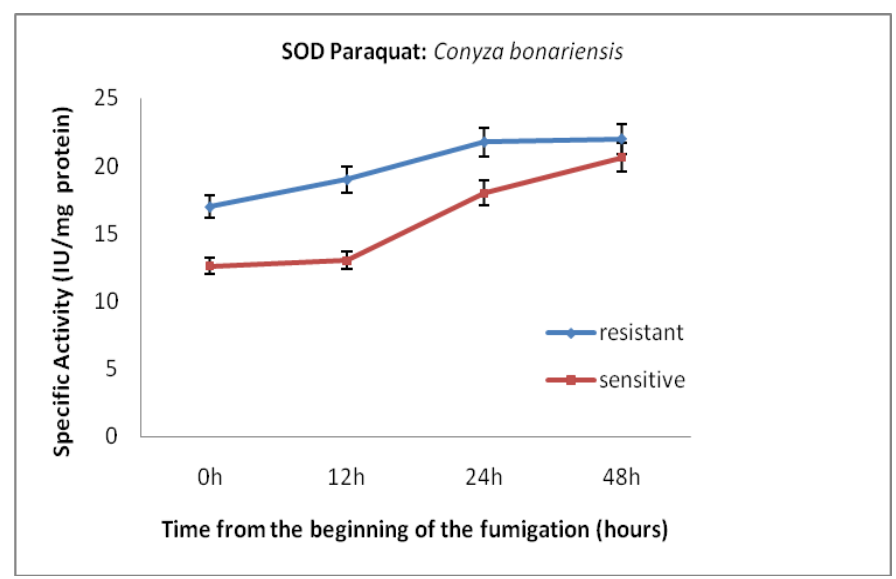

Figure 7: Time course of Superoxide dismutase activity in leaves extracts Conyza bonariensis (biotype resistant in closed circle and biotype sensitive in full triangle) after a treatment of paraquat $0.001 \%$ for 4 hours. 


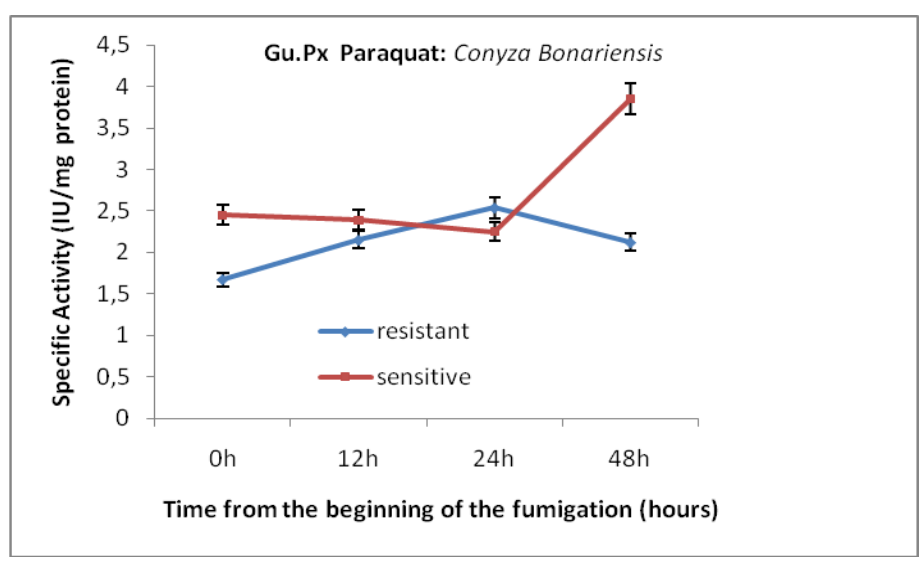

Figure 8: Time course of Guaiacol activity in leaves extracts Conyza bonariensis (biotype resistant in closed circle and biotype sensitive in full triangle) after a treatment of paraquat $0.001 \%$ for 4 hours.

\section{DISCUSSION}

Resistance to paraquat did not provide protection against ozone stress. Following either ozone fumigation or paraquat exposure in the two Conyza cultivars, there was a generalized increase of the enzymes activities. Apart the case of SOD after ozone fumigation (symptomatic treatment), there was no significant difference between the two cultivars at the enzymatic level. Ozone and paraquat did not use the same damage mechanism in Conyza.

It is commonly accepted that ozone stress, similarly to other abiotic stresses in plants, results in the induction of a number of enzymatic activities that increase the total antioxidative capacity of the organism (Bowler, 1992). In particular SOD, PX and catalase activities have been reported to undergo significant variations upon ozone exposure (Lee and Benett, 1982; Bowler et al., 1992; Tanaka, 1994 and paraquat (T.C. Stancliffe et al. 1971) also. However, up to now, data on enzymatic activities in response to ozone exposure are largely contradictory showing large interspecies differences Bowler et al. 1992). This large variability may be primarily due to the extreme complexity of the metabolic response of plants to ozone, which often results in the induction of strictly, several intercorrelated metabolic pathways. Often predominance of one of these pathways results in reduced activation, or even repression, of the others. For example efficient scavenging of toxic oxyradicals by alternative mechanisms may prevent activation of the enzymes of the Halliwell Asada cascade. (C.H. Foyer et B. Halliwel 1976).

Under normal conditions the basal levels of SOD and PX activities were similar in both cultivars, even if slightly higher in the ozone-tolerant one. However, this little difference cannot account for the large difference in the individual sensitivity to ozone: other biological mechanisms must exist to explain ozone resistance of Conyza.

Treatment of the two Conyza cultivars with ozone for 5 hours at $200 \mathrm{ppb}$ resulted in an expected effect. Indeed, a general increase of all the investigated enzymatic activities was clearly observed in both the ozone sensitive cultivar and the resistant one. This increase in PX and SOD activities took several hours to develop, being maximal only after 24 hours. Particularly significant is the case of APX and SOD for which an increment in activity of a factor $100 \%$ versus controls was observed. The long lag time needed to observe the raise in the enzymatic activities suggests that these processes are gene-mediated according to the classical description of enzymatic induction. So the increase in activity very likely corresponds to an increase in the expression level of these enzymes rather than to enzyme 
activation phenomena. It is of interest to note that a single episode of exposure to relatively low concentrations of ozone may be easily recognized even after 3-5 days (Diop et al.1997). The total protein content measured by the Bradford method did not change significantly in response to ozone exposure, suggesting that the observed variations in the enzyme activities are limited to the enzymes involved in the protection versus oxidative stress and do not correspond to general activation of protein synthesis. It must be noted, however, that a number of enzymatic activities increased simultaneously and to a similar extent, possibly in response to a common metabolic trigger signal.

The most relevant finding of our investigation, however, is represented by the large and expected difference in behaviour between the sensitive and the paraquat tolerant cultivar. A priori we would expect the situation, i.e. a larger increase of the antioxidant enzymatic activities of the paraquat tolerant cultivar compared to those of paraquat sensitive cultivar: indeed, a higher level of antioxidative capacity in the resistant cultivar would account easily for the different sensitivity to ozone. The fact that we have experimentally found this pattern may imply that in the ozone tolerant cultivar other more efficient and quicker mechanisms are operative that scavenge ozone attack; remarkably, similar effects have been already reported in the literature (Shaaltiel et al., 1988. This interpretation leads to the idea that induction of antioxidant enzymes represents a "second-line" defence system against ozone. When "first line" mechanisms are insufficient induction of antioxidant enzymes takes place.

\section{Conclusion}

The deep analysis of the biochemical parameters that we had monitotored could allow us to stablish at the beginning :

The totality of the stress and the intresecal sufferance of the plant;

i) The capcity of response ;

ii) The discrimination between sensitive and tolerant ;

iii) The identification of fundamental and biochemical systems for the response due to ozone.
Consequently, we have had to identify and to selection trustworthy bio marquers, which would be sensitive to stress, for which variations go in a coherent way.

We would propose to extend this work to other enzymes and/or at metabolites and /or at genes. The perspective consisted to selection a limited number of parameters at high definition in the different types of stress which would be used in application for the aim of biomonitoring.

\section{COMPETING INTERESTS}

The authors declare that they have no competing interests.

\section{AUTHORS' CONTRIBUTIONS}

This work was carried out in collaboration between all authors. CTD was the principal investigator. $\mathrm{LM}, \mathrm{DH}, \mathrm{CN}$ and GL also contributed significantly to the realization of this work. All authors read and approved the final manuscript.

\section{ACKNOWLEDGEMENTS}

We are grateful to Prof. Dr. J. GRESSEL, Department of Plant Genetics, Rehovot, Israel for providing Conyza bonariensis seeds.

\section{REFERENCES}

Ashton FM, Crafts AS. 1981. Mode of Action of Herbicides. Wiley: New York.

Bowler C, Van Montagu, Inze. 1992. Superoxide dismutase and stress tolerance. Annual Review of Plant Physiology and Plant Molecular Biology, 43: 83-116.

Bradford MM. 1976. A rapid and sensitive method for quantitation of microgram quantities of protein using the principle of protein dye-binding. Analytical Biochemistry, 72: 248-254.

Castagna, Ranieri. 2009. Detoxification and repair process of ozone injury: from $\mathrm{O}_{3}$ uptake to gene expression adjustment. Environ. Pollution, 157(5): 1461-1469.

Castillo, Greppin. 1986. Balance between anionic and cationic extracellular Peroxidase activities in Sedum album leaves after ozone exposure. Analyses by high performance liquid 
chromatography. Physiology Plantarum, 68: 201- 208.

Cord MC JM, Fridovitch I. 1969. Superoxide dismutase. An enzyme function for erythrocuprein (hemocuprein). Journal of Biological Chemistry, 244: 60496055.

Diop CT, Nali C, Messori L, Heimler D, Lorenzini G. 1997. Peroxidase and Superoxide dismutase Activities in Bean Leaves in response to ozone. Journal of Plant Pathology, 79(2): 107-113.

Dodge AD. 1982. The role of light and oxygen in action of photosynthetic inhibitor herbicides, in ACS symp. Ser. No 181. In Biochemical Response by Herbicides, Moreland DE, St John JJ, Hess FD (Eds); 58-57.

Foyer CH, Halliwell B. 1976. The presence of Glutathione and Glutathione reductase in chloroplasts: A proposal role in ascorbic acid metabolism. Planta, 133: 21.

Foyer CH, Lelandais M, Kunert KJ. 1994. Photooxidative stress in plants. Plant Physiology, 92: 696-717.

Gressel G, Galun. 1994. Genetic control of photo oxidative tolerance. In Causes of Photo Oxidative Stress and Amelioration of Defence system in Plants, Foyer $\mathrm{CH}$, Mulineaux PM (Eds). CRC Press: Boca Raton Fl; 237-274.

Harris N, Dodge. 1972. The effect of paraquat on flax cotyledon leaves: physiological and biochemical changes. Planta, 104: 210.

Langebartels C, Kerner K, Leonardi S, Schraudner M, Trost M, Heller W, Sandermann HJr. 1991. Biochemical plant responses to ozone I. Differential induction of polyamine and ethylene biosynthesis in tobacco. Plant Physiol., 95: 882-889.

Lebaron H, Gressel J. 1982. Herbicide Resistance in Plants. Wiley: New York.

Lee EH, Benett JH. 1982. Superoxide dismutase. A possible protective enzyme against ozone injury in snapbean (Phaseolus vulgaris L.). Plant Physiology, 69: 1444-1449.
Loenzini G, Bonati MP, Nali C, Fornasiero BR. 1994. The protective effect of rust infection against ozone, sulfur dioxide and paraquat toxicity symptoms in broad bean. Physiological and Molecular Plant Pathology, 45: 263-279.

Lorenzini G, Stringari S, Nali C. 2002. The absence of cross tolerance between ozone and paraquat: the case of Conyza bonariensis. Phyton, 43(2): 89-96.

Luwe MWF, Takahama U, Heber U. 1993. Role of ascorbate in detoxifing ozone in the apoplast of spinach (Spinacia oleracea L.). Plant physiology, 101: 969-976.

Paoletti E, Nali C, Lorenzini G. 2007. Early Responses to Acute Ozone Exposure in Two Fagus Sylvatica Clones Differing in Xeromorphic Adaptations: Photosynthetic and Stomatal Processes, Membrane and Epicuticular Characteristics. Environmental Monitoring and Assessment, 128 (1-3): 93-108(16).

Rabinovitch HD, Fridovitch. 1983. Superoxide radicals, Superoxide dismutase and oxygen toxicity in plants, Photochemistry Photobiol., 37: 679.

Ranieri A, D'Urso G, Nali C, Lorenzini G, Soldatini GF. 1996. Ozone stimulates apoplastic systems in pumkin leaves. Physiologia Plantarum, 97: 381-387.

Shaaltiel Y, Gressel J. 1986. Multienzyme oxygen radical detoxifying system correlated with paraquat resistance in Conyza bonariensis. Pesticide Biochemistry and Physiology, 26: 22-28.

Stancliffe TC, Pirie A. 1971. The Production of Superoxide radical in reactions of the herbicides diquat. FEBS Lett., 17: 297.

Tanaka K. 1994. Tolerance to herbicides and air pollutants. In Foyer $\mathrm{CH}$, Mullineaux PM (eds). Causes of photooxidative stress and amelioration of defence systems in plants. CRC Press: Boca Raton, FL, USA; 365-378. 